\title{
Continuous Scanning Technique with Barkhausen Magnetic Noise for Carbon Steel Sheets
}

\author{
Leosdan Figueredo Noris ${ }^{a, b}$, Linilson Rodrigues Padovese ${ }^{b}$, Sérgio Souto Maior Tavares ${ }^{c *}$,
}

\author{
Juan Manuel Pardal ${ }^{a, c}$ \\ ${ }^{a}$ Programas de Pós-Graduação em Engenharia Mecânica (PGMEC) e Montagem Industrial, \\ Universidade Federal Fluminense - UFF, Rua Passo da Pátria, 156, CEP 24210-240, Niterói, RJ, \\ Brasil \\ ${ }^{b}$ Departamento de Engenharia Mecânica, Escola Politécnica, Universidade de São Paulo - USP, Av. \\ Prof. Mello Moraes 2231, 05508-900, SP, Brasil \\ cPrograma de Pós-graudação em Engenharia Mecânica e Tecnologia de Materiais - Centro Federal de \\ Educação Celso Suckow da Fonseca - CEFET-RJ, Av. Maracanã, 229, Bloco E, 5ªndar 20271-110, \\ Rio de Janeiro, RJ, Brasil
}

Received: May 24, 2018; Revised: October 03, 2018; Accepted: November 16, 2018

\begin{abstract}
This work studies the application of a Non-Destructive Inspection Technique (NDIT), based on the Magnetic Barkhausen Noise (MBN), for the detection of non-homogeneous regions in carbon steel plates. It presents the advances in the development of a variant of a new non-destructive magnetic test technique, called Continuous Scanning Magnetic Barkhausen Noise (CSMBN). The non-homogeneous or damaged regions were produced by plastic deformations in rolled and annealed sheets of SAE 1060 and 1070 steels.MBN is generated by abrupt changes in the magnetization of materials when subjected to alteration. The sensitivity of the MBN signals in the detection of plastic deformations was analyzed varying parameters such as excitation magnetic field frequency and the speed of movement of the probe. The behavior of the root mean square of magnetic Barkhausen Noise signal $\left(\mathrm{RMS}_{\mathrm{MBN}}\right)$ parameter was correlated with the position of the nonhomogeneous regions detected in the samples. An evaluation of the technique applied to the measurement was made, comparing the results obtained with the Static Magnetic Barkhausen Noise (SMBN) technique, which is a method already established in the literature. The results showed that in all cases studied it was possible to detect the position of the damage, due to variation of the magnetic field. These changes are affected by the presence and distribution of elastic stresses (compression and traction), plastic deformation and microstructure modification. The results of CSMBN were similar to the SBMN with the advantage of being a continuous and more productive procedure. This new technique increases the spectrum of NDIT solutions for problems not contemplated by existing techniques.
\end{abstract}

Keywords: Barkhausen Magnetic Noise, Non Destructive Testing, Plastic Strain, Stress, Barkhausen Continuous, Surface Mapping.

\section{Introduction}

The design of mechanical and structural components in engineering is limited by the mechanical properties of the materials as well as by the methods used in their manufacture. Once in service the components will undergo thermo-chemical processes that changes their characteristics and affect the projected life.

In this context, the use of Non-destructive Testing (NDT) methods plays an important role on the evaluation of damage that affect the life of the component.

A wide range of Non-Destructive Inspection techniques (NDIT) has been developed to address these problems. Most of them cannot detect changes in the microstructure, because they only detect volumetric defects such as pores and cracks.

Although the use of NDIT does not guarantee that a failure will not happen, they play a very important role, which is to minimize the chances of failure and to maximize system availability.

The Barkhausen Magnetic Noise (MBN) technique has been widely used in the NDIT area. For more than 14 years, the Dynamics and Instrumentation Laboratory (LADIN) of the University of São Paulo has developed proprietary NDIT technology based on MBN. This development covers the manufacture of equipment, software and technological applications.

The MBN is a technological alternative with great potential, above all for its low cost, simplicity of use and for opening possibilities of characterization of ferromagnetic materials that are not possible with other NDIT.

Some industrial applications of $\mathrm{MBN}$ measurement technique are:

- $\quad$ Process and quality control in the production of gears, valves, bearings, crankshaft, valve control, and other important parts of engines and aircraft. 
- Evaluation of contact fatigue damage in gears and bearings.

- Evaluation of residual stresses in welded pipes and rolling cylinders.

- Evaluation of the shot peening effect in steel.

- Measurement of the inversion of residual stresses in railway wheels by thermal effect.

- Evaluation of thermal degradation in boiler pipes.

- Detection of phase transformations and precipitation reactions in ferromagnetic alloys ${ }^{1-2}$.

- Detection of temper embrittlement in steels ${ }^{3}$.

The aim of this work is to study and develop a surface scanning technique, based on Continuous Scanning Magnetic Barkhausen Noise (CSMBN), for the detection of nonhomogeneous regions, related to sub and microstructural changes, in carbon steel plates. The influences of the scanning speed and the excitation frequency in the detection of non-homogeneous regions are evaluated. The results of continuous inspection (CSMBN) are compared to the static procedure (SMBN).

\section{Classical Barkhausen Magnetic Noise and Non-Destructive Testing}

The Barkhausen Effect is a phenomenon of discontinuous changes in flux density within a ferromagnetic material when subjected to a variable magnetic field. This was first discovered by the German scientist Heinrich Barkhausen ${ }^{4}$. He discovered that during the magnetization of an iron rod, short voltage electric pulses are induced in a coil wound around the bar. These pulses were detected as audible clicks on a speaker.

Most Barkhausen events are produced by the irreversible movement of $180^{\circ}$ domain walls, and occur in the region of greater slope of the magnetization curve ${ }^{5,6}$. In the advancement of the magnetization process, other factors begin to contribute, as the motion of walls of $90^{\circ}$, rotation of domains, and annihilation of walls. As the process approaches magnetic saturation, the motion of walls disappears ${ }^{7}$. The location of the maximum pulses that make up the MBN was found shortly before the coercive field ${ }^{8}$.

Statistical analysis of the MBN signal can provide information on the interaction between domain walls and the configuration of stresses, deformations or on the microstructure features of the material.

\subsection{MBN continuous}

In the classical technique an electromagnet produces an alternating magnetization between its poles while a reader coil is fixed on the surface of the material to capture the magnetic response thereof. Therefore, it is considered as a Static Barkhausen Magnetic Noise Measurement (SMBN).

On the other hand, a new "continuous Barkhausen" $(\mathrm{CMBN})$ measurement technique was created in which the probe is moved at constant speed over the sample, and the Barkhausen noise is monitored continuously ${ }^{9}$. This new technique was used in the inspection of mechanical defects in pipes.

Also in Desvaux et al. ${ }^{10}$, a real-time instrumentation was designed to estimate the degree of residual stresses in the contact zone between the balls and the runway. This method has the advantage of being reliable and applicable to the geometry of circular rings.

The CMBN method was later used by Franco ${ }^{11}$ in his doctoral thesis. In this work, volumetric defect mapping results were obtained, which were later published corroborating some of the observations of $\mathrm{Crouch}^{12}$, such as the effect of velocity and field strength on the obtained MBN quality.

Subsequently, Ilker et al. ${ }^{13}$ used a continuous-motion probe with a highly cyclic excitation (around hundreds of $\mathrm{Hz}$ ), which allows to inspect residual stresses inserted in the welding process.

In another more recent work a magnetic NDT technique based on the Barkhausen effect, called Barkhausen Continuous Rotational Magnetic Noise (CRMBN), was developed. This technique was used satisfactorily to perform real-time highresolution magnetic anisotropy measurements, exceeding the technical limitations of classic $\mathrm{MBN}^{14}$.

The above mentioned work of Franco and Morgan, developed in the LADIN, is an important advance in this technique, that until the moment, has received a little attention. In both works, new applications were explored, overcoming in the process many stability problems. The techniques, while still at a stage of development, offer promising alternatives for applications in the industry.

\section{Experimental Procedures}

\subsection{Materials}

Two carbon steel plates were used, a low carbon SAE 1006 and high carbon SAE 1070, with chemical compositions shown in Table 1. Both materials were cold rolled and annealed, without skin pass after annealing. Cold reduction was about $60 \%$ in seven passes for SAE 1006 and $45 \%$ in 5 passes for SAE 1070 steel. Annealing of SAE 1006 steel was done at $900^{\circ} \mathrm{C}$, while SAE 1070 steel was annealed at $820^{\circ} \mathrm{C}$. In both cases the sheets were slowly cooled after soaking. The microstructures obtained are shown in Figs. 1(a-b).SAE 1006 has a typical ferritic structure with reduced pearlite and some free $\mathrm{Fe}_{3} \mathrm{C}$ carbides. SAE 1070 has coarse pealite with small portions of pro-eutectoid ferrite.

Table 1. Chemical compositions of steels (\% wt.)

\begin{tabular}{cccccc}
\hline Steel plate & $\mathrm{C}$ & $\mathrm{Mn}$ & $\mathrm{P}$ & $\mathrm{S}$ & $\mathrm{Si}$ \\
\hline SAE 1006 & 0.040 & 0.261 & 0.015 & 0.0066 & - \\
SAE 1070 & 0.712 & 0.610 & 0.018 & 0.0010 & 0.24 \\
\hline
\end{tabular}




\subsection{Pattern preparation}

Three lines were drawn in the samples (yellow lines in Fig. 2), parallel to the rolling direction, through which the measuring probe would pass. Measurements of SMBN were carried out in the sample set with the aim of find nonhomogeneous zones and use them as a pattern for comparison to measurements made with CSMBN. Localized plastic deformations were produced in two points along each yellow line. An hydraulic press and a rectangular penetrator were used to produce indentations with $45 \mathrm{x} 4 \mathrm{~mm}$ dimensions, applying a controlled pressure of $110 \mathrm{kPa}$. The indentations had the longitudinal axis $(45 \mathrm{~mm})$ perpendicular to the yellow line, as indicated in blue color in Fig.2.

In the case of discrete (point-to-point) inspection, measurements were made every centimeter on both sides of the localized plastic deformation. Considering 4 measurements in each side of the two indentations, plus the exact points of indentations, it results in 18 positions, as can be seen in Fig.2.
The two red lines indicate the points were the measurements by continuous scanning (CSMBN) start and end.

SMBN and CSMBN inspection were performed in the sheets before plastic deformation, for comparison.

\subsection{Equipment and methods used in CSMBN}

The standard arrangement for the CSMBN is shown in Fig. 3.

The total control of the system was accomplished through the software BarkView developed in LADIN. The equipment is responsible for generation and control of the excitation current, as well the acquisition and filtering of the voltage signals generated by the MBN sensor. Using a bipolar source, the "BarkTech" generates sinusoidal excitation currents with frequencies of 0.4 to $100 \mathrm{~Hz}$, and amplitudes of excitation from 0 to 5A. MBN signals can be acquired in different frequency ranges and amplified with different gain values. All these functions are controlled by the computer. During the measurement process, the sample

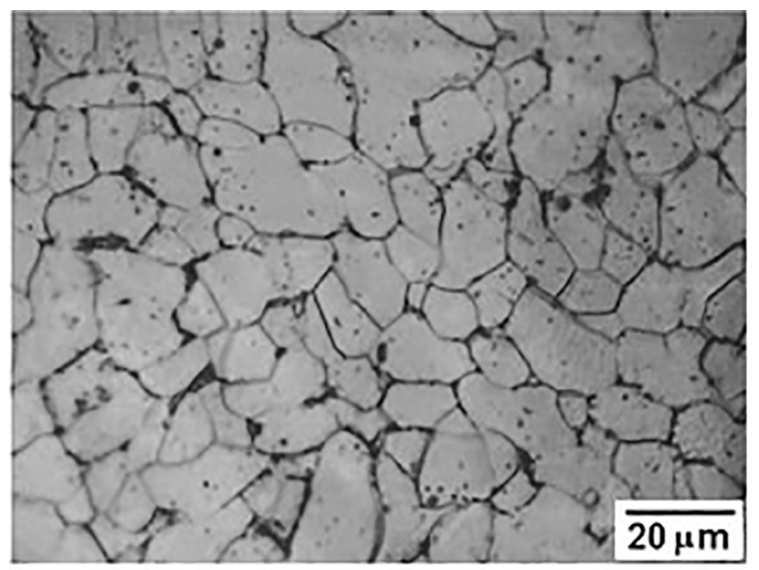

(a)

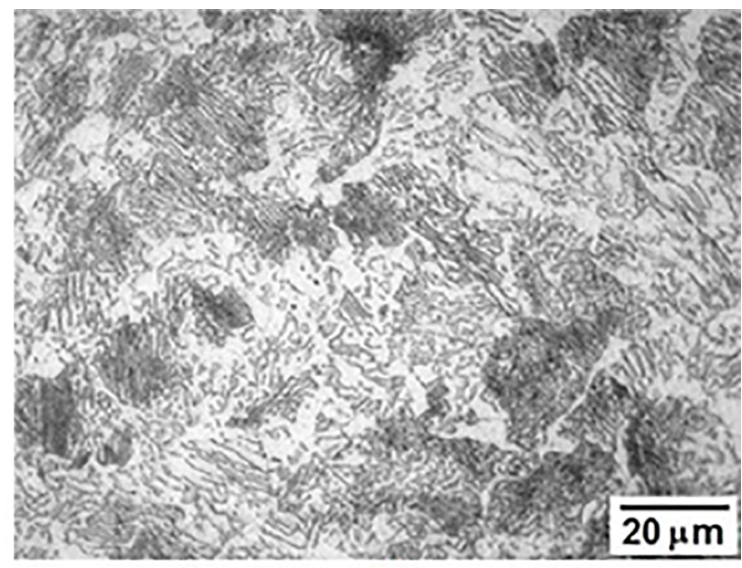

(b)

Figure 1. Microstructure of (a) SAE 1006 and (b) SAE 1070.
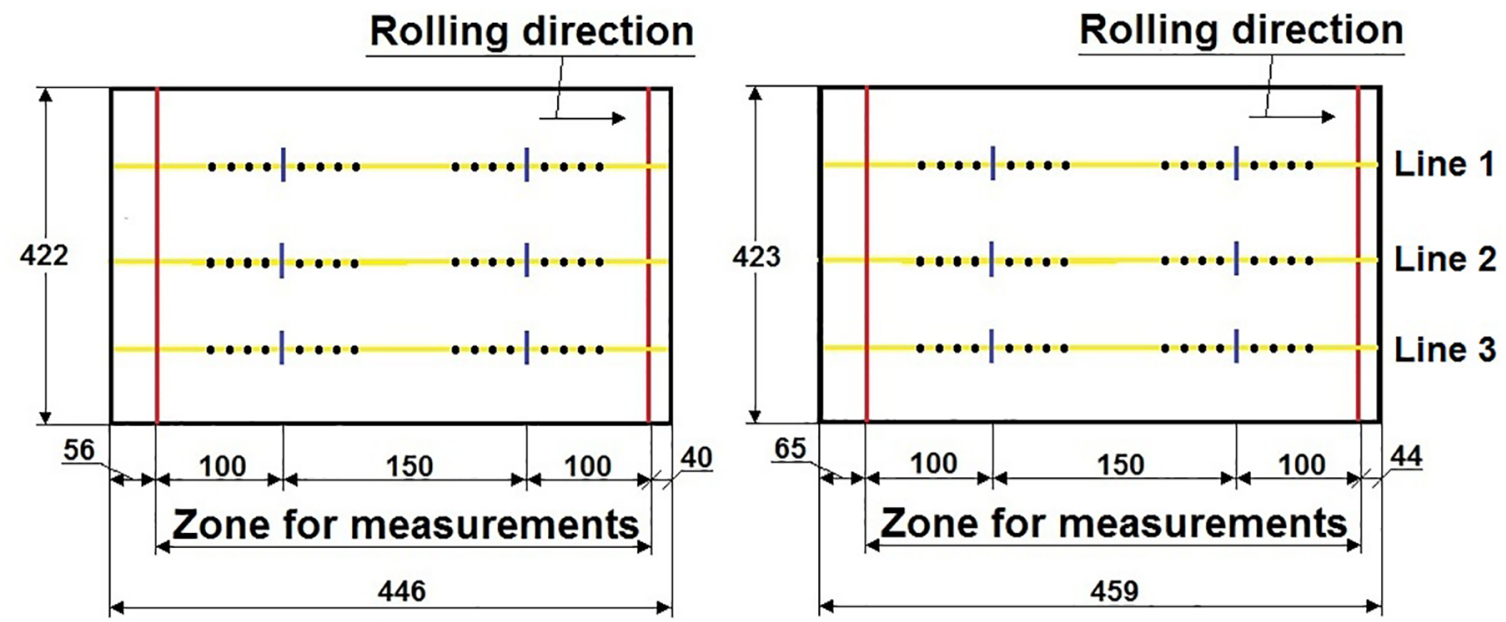

Figure 2. Geometry and dimensions of the samples in (mm), and areas where MBN measurements were performed: (a) SAE 1006 (left) and (b) SAE 1070 (right). 
always remained static, and the probe moved at different speeds in the horizontal direction.

The current wave injected into the electromagnets was always sinusoidal at frequencies of 5 and $10 \mathrm{~Hz}$. All signals from the MBN probe were acquired at a sampling frequency of $450 \mathrm{kHz}$.

For the control of the movement a cart was developed, in which the probe is positioned as can be seen in Fig. 4. Therefore, the movement of the probe is performed by this trolley, which moves on the samples. The control is performed through an Arduino UNO microcontroller, which allows to vary the speed and determine the position of the cart at each instant of time.

The signal processing method developed by Padovese et al. ${ }^{15}$ was used in the analysis of CSMBN signals. In this

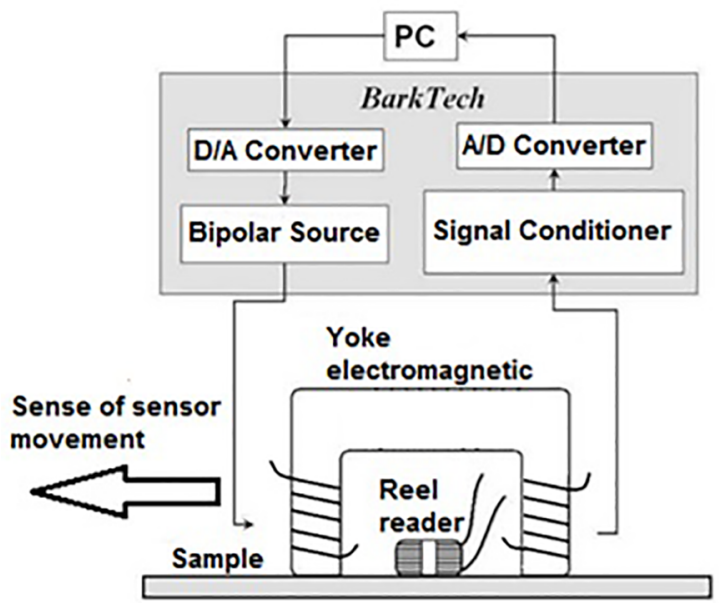

Figure 3. Experimental setup for acquisition of CSMBN.
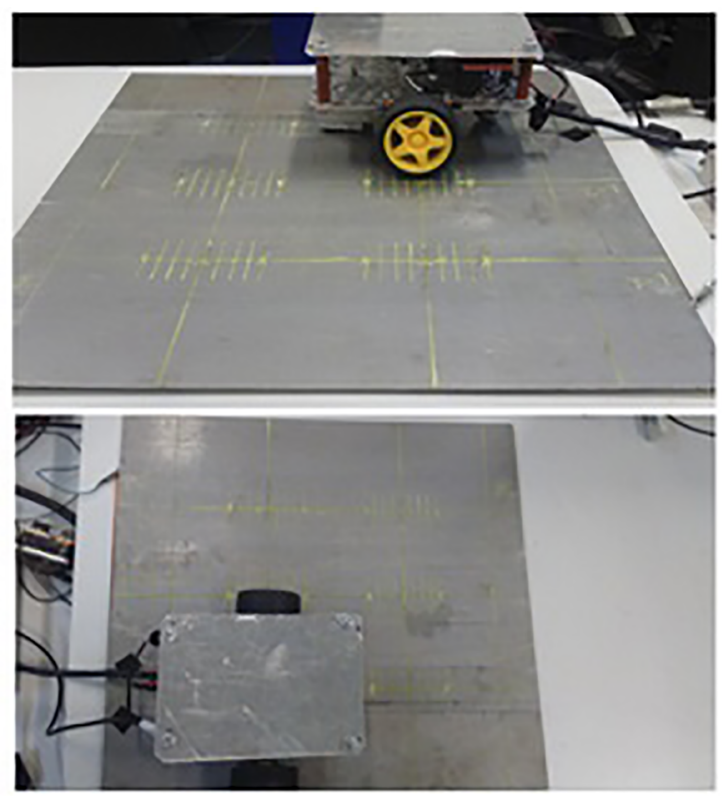

Figure 4. Image of the cart and probe used for the CSMBN. methodology they calculated the root mean square values of the magnetic Barkhausen Noise $\left(\mathrm{RMS}_{\mathrm{MBN}}\right)$ according to:

$$
R M S_{R M B}=\sqrt{\sum_{i}^{n} \frac{\left(V_{i}-V_{a}\right)^{2}}{n-1}}
$$

Where $\mathrm{V}_{\mathrm{i}}$ is the voltage value of a pulse and $\mathrm{V}_{\mathrm{a}}$ is the average voltage value of all $n$ pulses of the Barkhausen signal.

The plates were locally damaged by controlled plastic deformation as will be described.

\subsection{Magnetic signal measurement procedure}

The signals were acquired for two complete periods of current (two MBN signals). The MBN signals were acquired with different measurement parameters:

- Excitation frequencies: 5 and $10 \mathrm{~Hz}$.

- Excitation currents: 3 A.

- Signal acquisition: Each measurement is composed of MBN signals generated in two complete magnetization cycles. The sampling rate was maintained at $450 \mathrm{kHz}$. And 10 repetitions of each measurement condition were recorded.

- Probe Orientation: The orientation of the probe controls the direction of the magnetic field. Thus, MBN measurements were made by magnetizing the sample towards the rolling direction $(\mathrm{RD})$ that coincides with the direction of easy magnetization.

- Scanning speed: Five speeds were used for conducting the search $(14,16,19,22$ and $25 \mathrm{~mm} / \mathrm{s})$.

\section{Results}

The results show that the evolution of the $\mathrm{RMS}_{\mathrm{MBN}}$ parameter obtained with the SMBN technique was similar

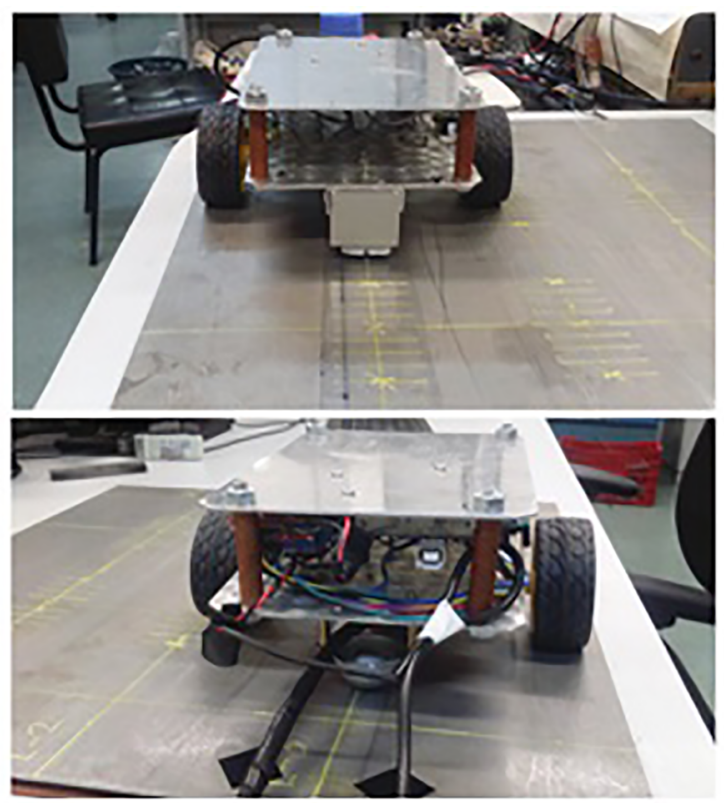


to behavior of $\mathrm{RMS}_{\mathrm{MBN}}$ parameter obtained with CSMBN inspection. In both cases it was possible to identify the position of the two deformations zones inserted in the samples. As expected, the $\mathrm{RMS}_{\mathrm{MBN}}$ values, and therefore the Barkhausen signal, decreased with increasing plastic deformation. This is explained by the high density of dislocations present in these zones of the material, making more difficult to move the domain walls during magnetization.

\subsection{Preliminary study 1. Detection of non- homogeneous zones using the SMBN technique}

As the conceptual gaps in the application of the technique are large, due to complexity, a preliminary phase of preliminary tests was performed. The objective was to evaluate proposals of measurement procedures, probe configurations, methods of signal analysis, and other factors that could determine the feasibility of applying the new technique in the detection of material damage.

Based on the experience gained in classical MBN measurements (static measurements), samples with easily detectable plastic deformations were designed. Thus, the measurement parameters and preliminary results of SMBN were obtained.

The results for the case of the discrete measurement on both steel plates are shown in Figs. 5 and 6 , for $5 \mathrm{~Hz}$ and $10 \mathrm{~Hz}$, respectively. In both frequencies, a decrease in $\mathrm{RMS}_{\mathrm{MBN}}$ values in the positions 5 and 14 were observed, which corresponds to the locations of the indentations.

\subsection{Preliminary study 2. Detection of non- homogeneous zones using the CSMBN technique}

This section presents the results of tests performed with five scanning speeds $(14,16,19,22$ and $25 \mathrm{~mm} / \mathrm{s})$. Figs. 7 to 11 show the variation of the $\mathrm{RMS}_{\mathrm{MBN}}$ parameter of the signal, for each scanning speed, with excitation frequency $5 \mathrm{~Hz}$. It is observed that with the 5 speeds used, the technique can detect and locate the plastic deformations

\section{Discussion}

It can be verified that the $\mathrm{RMS}_{\mathrm{MBN}}$ parameter profile shows how the Barkhausen signal decreases with the localized plastic deformation, which is a typical response in SMBN measurements. The high density of dislocations introduced by plastic deformation hinders the movement of the domain walls.

From the analysis of Figs. 7-11(5 Hz) and 12-16 $(10 \mathrm{~Hz})$ it is observed that the technique can detect the location of the plastic deformation with all five speeds used. It can also be observed that the speed variation within the 14 to $25 \mathrm{~mm} / \mathrm{s}$ range does not have a significant influence on detection. Therefore, higher speeds can be used, which results in an advantage of the technique when considering its application in the industrial area.

The influence of the excitation frequency can be analyzed with the aid of Fig.17. It is observed that the increase of
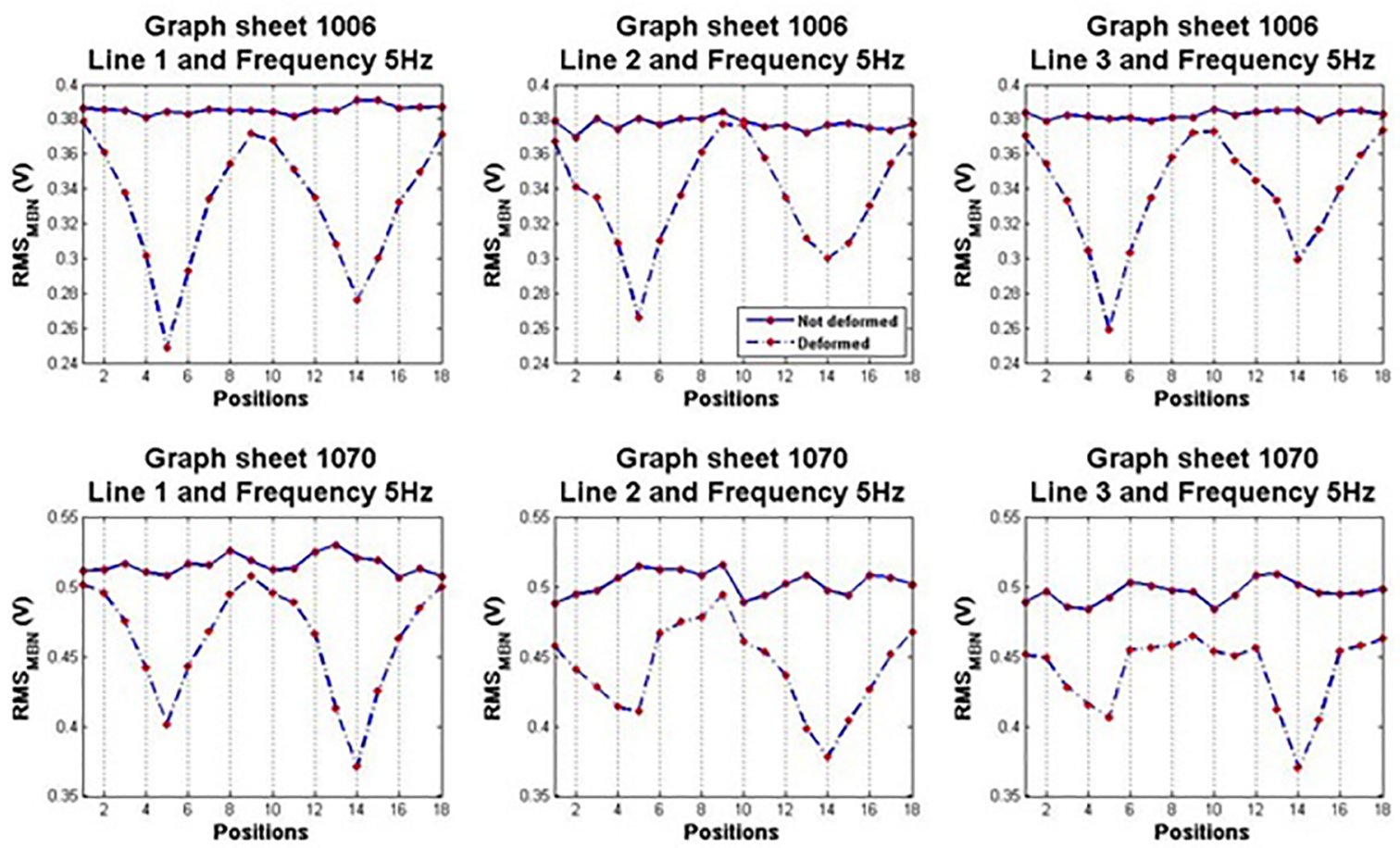

Figure 5. Graphs for SAE 1006 and SAE 1070 sheets, lines 1, 2 and 3; Frequency 5Hz before and after deformation, discrete measurement (SMBN). 
Graph sheet 1006

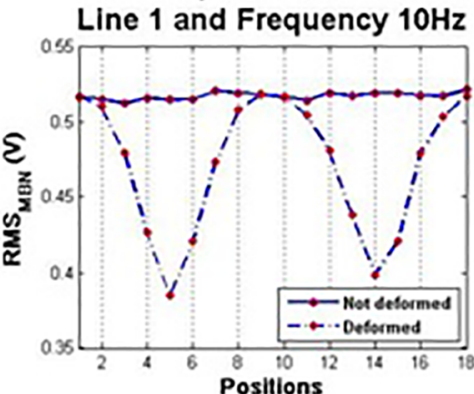

Graph sheet 1070

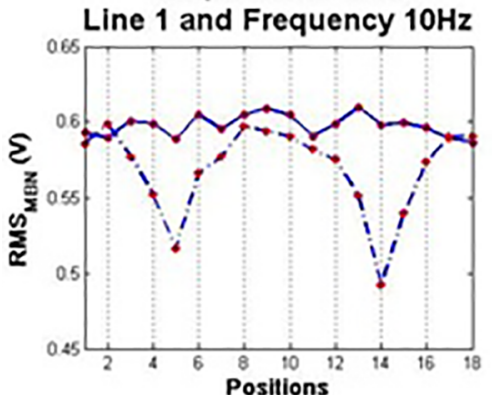

Graph sheet 1006

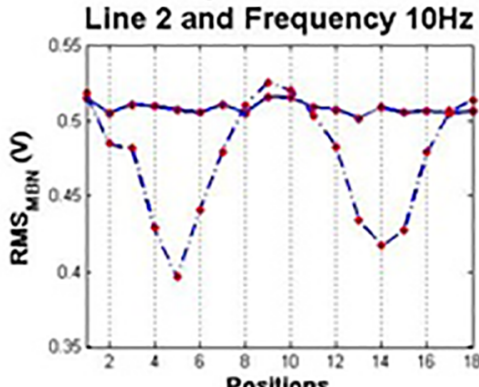

Graph sheet 1070 Line 2 and Frequency $10 \mathrm{~Hz}$

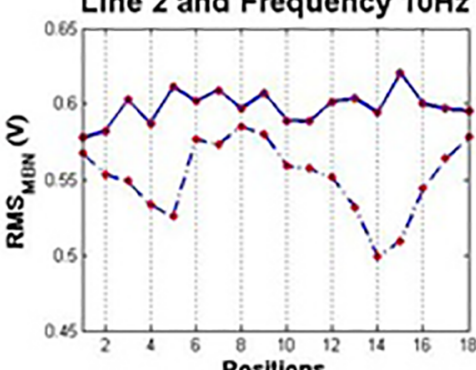

Graph sheet 1006 Line 3 and Frequency $10 \mathrm{~Hz}$

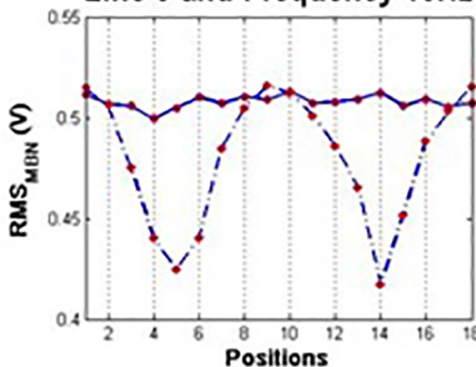

Graph sheet 1070 Line 3 and Frequency $10 \mathrm{~Hz}$

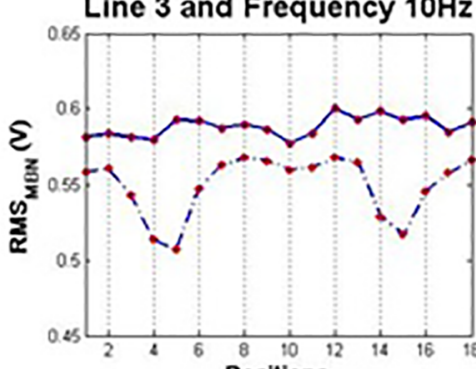

Figure 6. Graphs for SAE 1006 and SAE 1070 sheets, lines 1, 2 and 3; Frequency 10Hz before and after deformation, discrete measurement $(\mathrm{SMBN})$

Graph sheet 1006

Line 1 and Frequency $5 \mathrm{~Hz}$

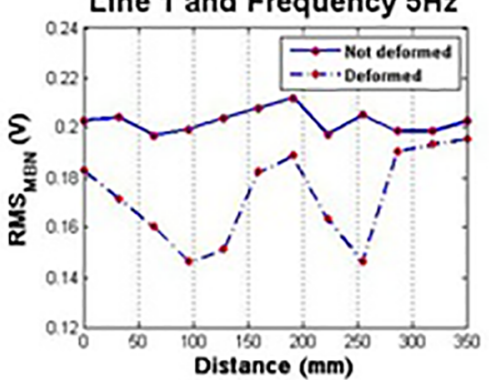

Graph sheet 1070

Line 1 and Frequency $5 \mathrm{~Hz}$

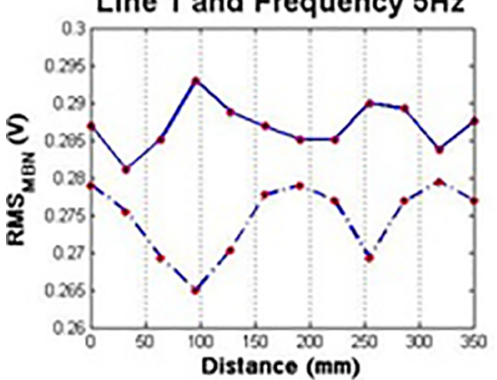

Graph sheet 1006 Line 2 and Frequency $5 \mathrm{~Hz}$

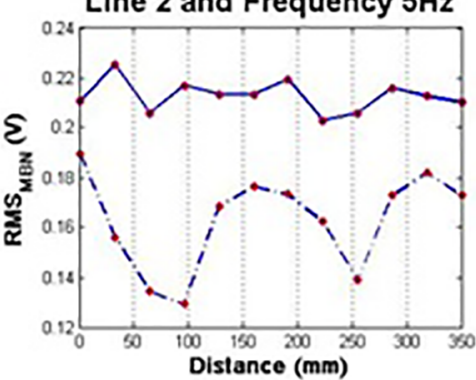

Graph sheet 1070 Line 2 and Frequency $5 \mathrm{~Hz}$

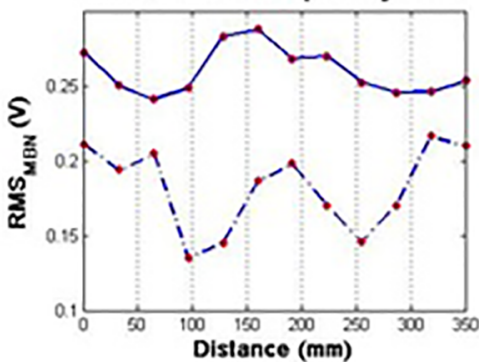

Graph sheet 1006 Line 3 and Frequency $5 \mathrm{~Hz}$

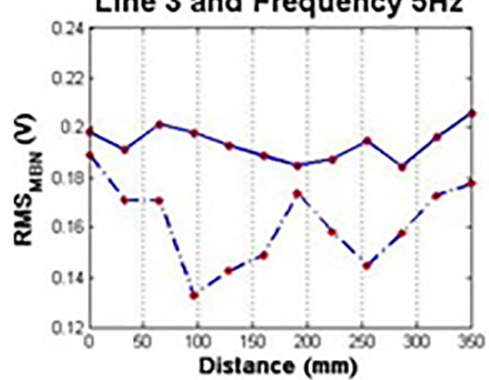

Graph sheet 1070 Line 3 and Frequency $5 \mathrm{~Hz}$

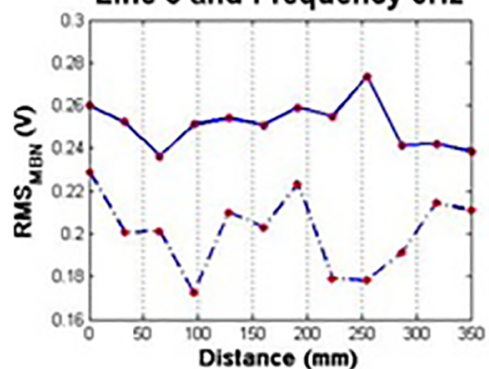

Figure 7. Graphs for SAE 1006 and 1070, lines 1, 2 and 3, frequency $5 \mathrm{~Hz}$, and speed $14 \mathrm{~mm} / \mathrm{s}$. 

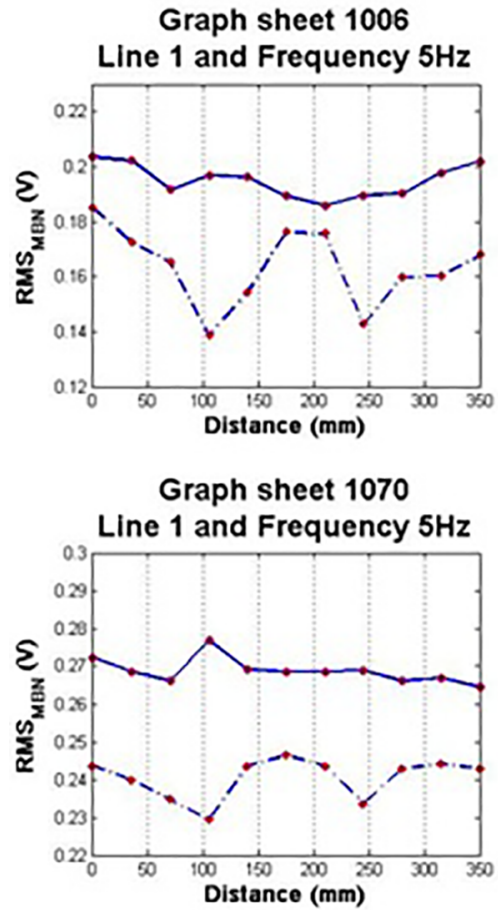

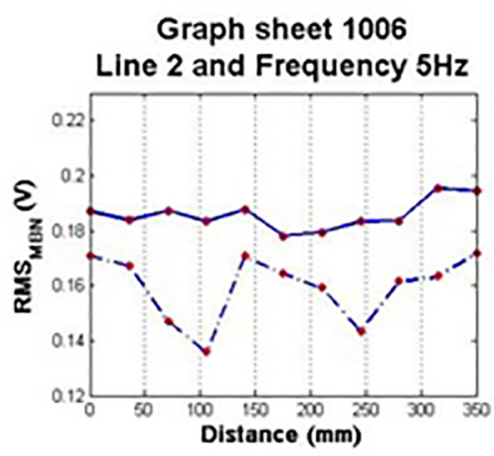

Graph sheet 1070

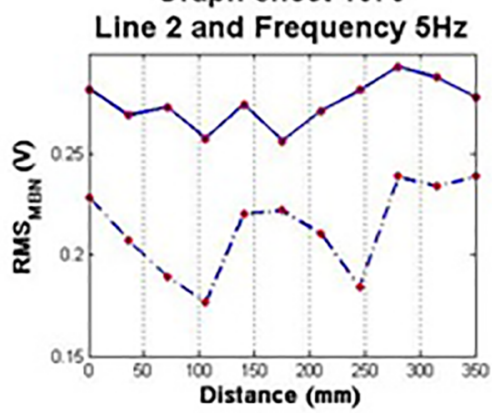

Graph sheet 1006 Line 3 and Frequency $5 \mathrm{~Hz}$

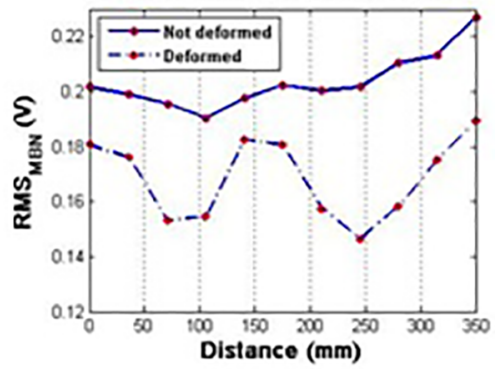

Graph sheet 1070 Line 3 and Frequency $5 \mathrm{~Hz}$

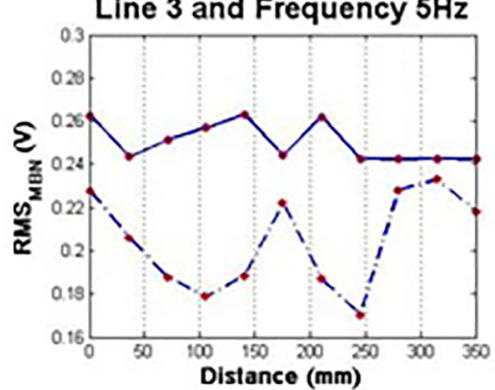

Figure 8. Graphs for SAE 1006 and 1070, lines 1, 2 and 3, frequency $5 \mathrm{~Hz}$, and speed $16 \mathrm{~mm} / \mathrm{s}$.

Graph sheet 1006 Line 1 and Frequency $5 \mathrm{~Hz}$

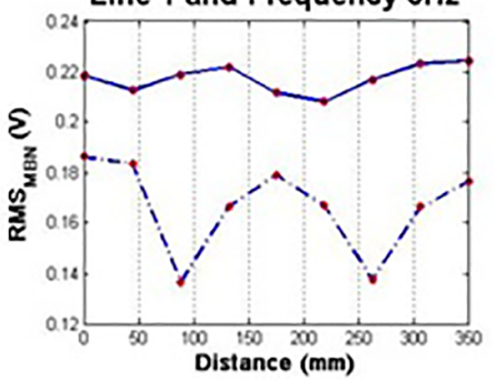

Graph sheet 1070 Line 1 and Frequency $5 \mathrm{~Hz}$

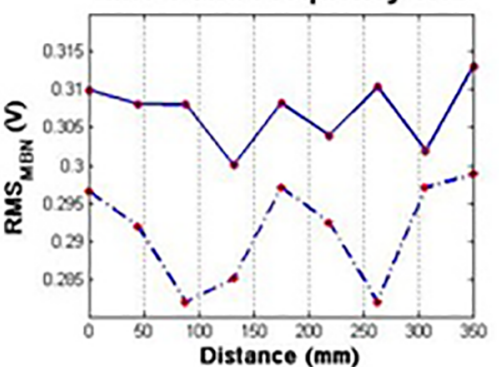

Graph sheet 1006 Line 2 and Frequency $5 \mathrm{~Hz}$

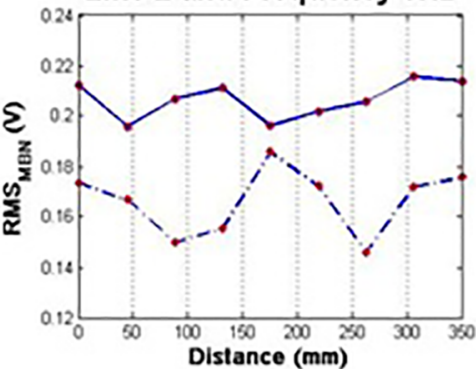

Graph sheet 1070 Line 2 and Frequency $5 \mathrm{~Hz}$

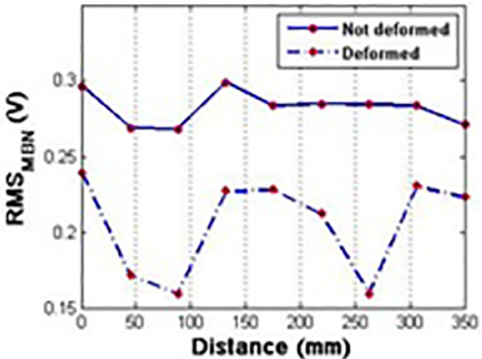

Graph sheet 1006 Line 3 and Frequency $5 \mathrm{~Hz}$

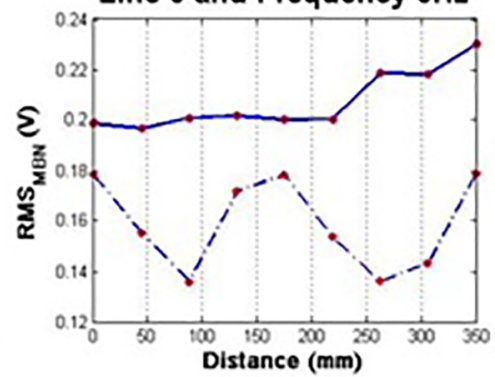

Graph sheet 1070 Line 3 and Frequency $5 \mathrm{~Hz}$

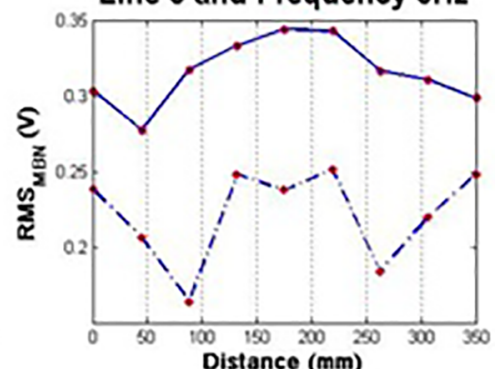

Figure 9. Graphs for SAE 1006 and 1070, lines 1, 2 and 3, frequency 5Hz, and speed $19 \mathrm{~mm} / \mathrm{s}$. 


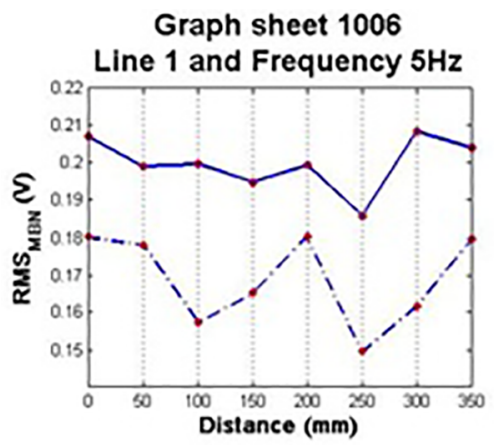

Graph 1070 Line 1 and Frequency $5 \mathrm{~Hz}$

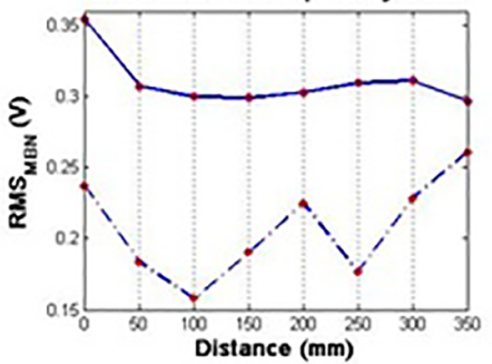

Graph sheet 1006 Line 2 and Frequency $5 \mathrm{~Hz}$

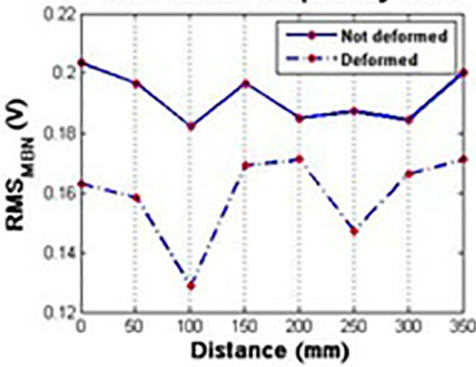

Graph sheet 1070 Line 2 and Frequency $5 \mathrm{~Hz}$

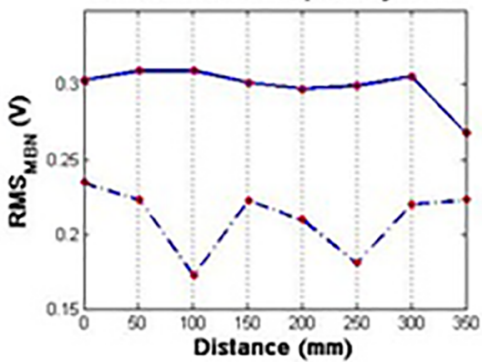

Graph sheet 1006 Line 3 and Frequency $5 \mathrm{~Hz}$

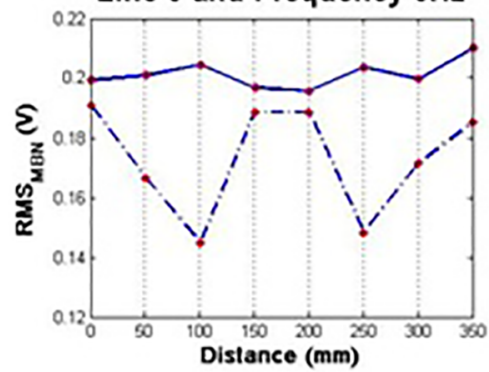

Graph sheet 1070 Line 3 and Frequency $5 \mathrm{~Hz}$

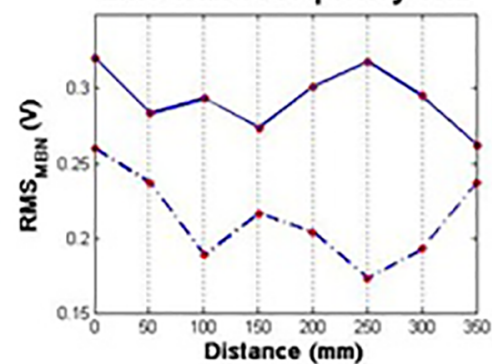

Figure 10. Graphs for SAE 1006 and 1070, lines 1, 2 and 3, frequency 5Hz, and speed $22 \mathrm{~mm} / \mathrm{s}$.

Graph sheet 1006 Line 1 and Frequency $5 \mathrm{~Hz}$

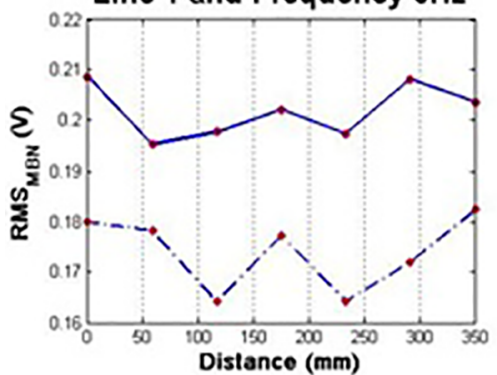

Graph sheet 1070

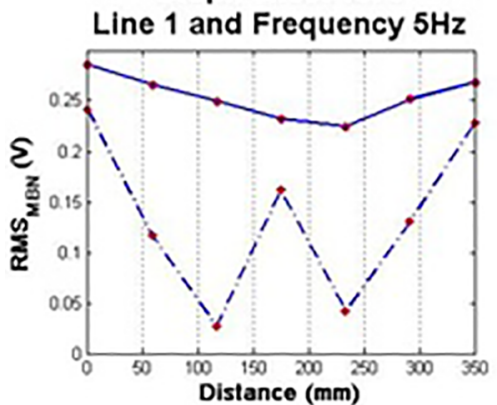

Graph sheet 1006

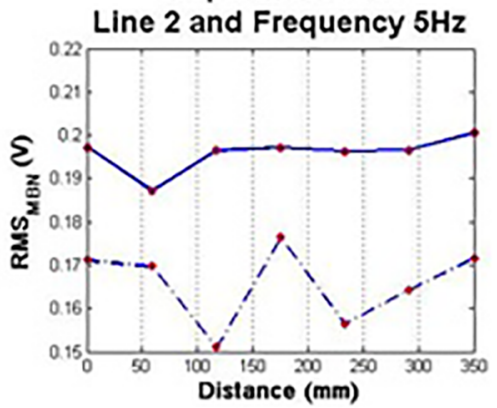

Graph sheet 1070

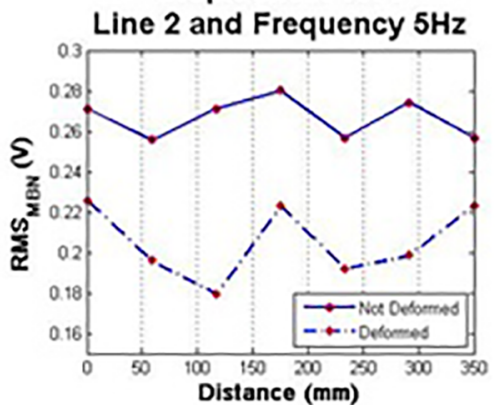

Graph sheet 1006 Line 3 and Frequency $5 \mathrm{~Hz}$

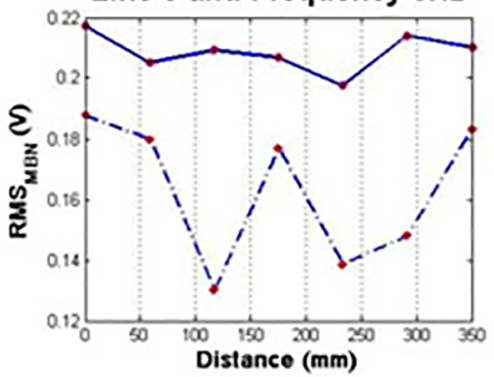

Graph sheed 1070 Line 3 and Frequency $5 \mathrm{~Hz}$

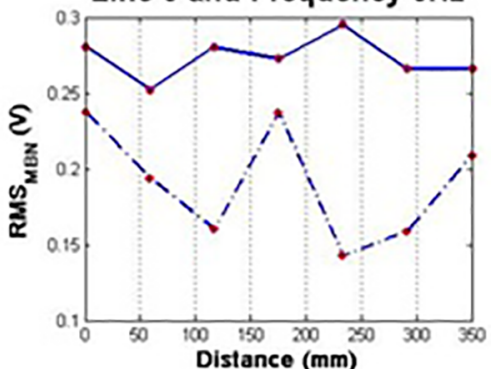

Figure 11. Graphs for SAE 1006 and 1070, lines 1, 2 and 3, frequency $5 \mathrm{~Hz}$, and speed $25 \mathrm{~mm} / \mathrm{s}$. 


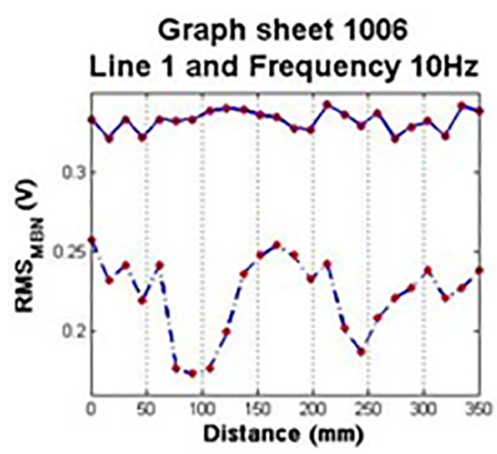

Graph sheet 1070 Line 1 and Frequency $10 \mathrm{~Hz}$

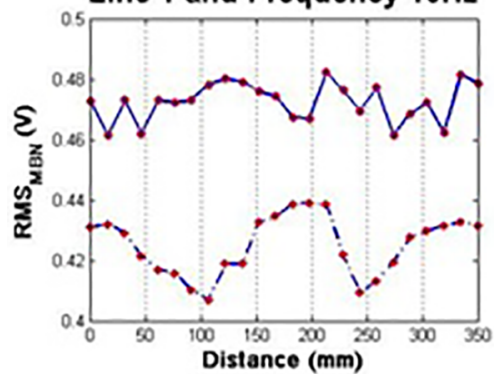

Graph sheet 1006 Line 2 and Frequency $10 \mathrm{~Hz}$

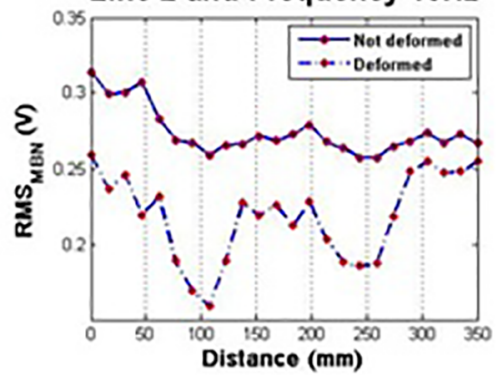

Graph 1070 Line 2 and Frequency $10 \mathrm{~Hz}$

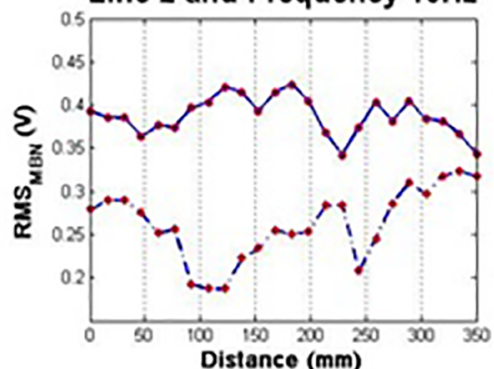

Graph sheet 1006 Line 3 and Frequency $10 \mathrm{~Hz}$

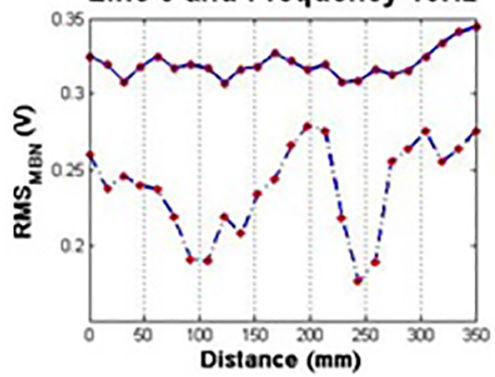

Graph sheet 1070 Line 3 and Frequency $10 \mathrm{~Hz}$

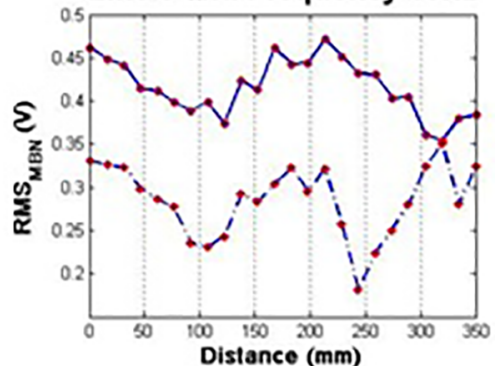

Figure12. Graphs for SAE 1006 and 1070; Lines 1, 2 and 3; Frequency 10Hz; Speed 14 mm/s.

Graph sheet 1006 Line 1 and Frequency $10 \mathrm{~Hz}$

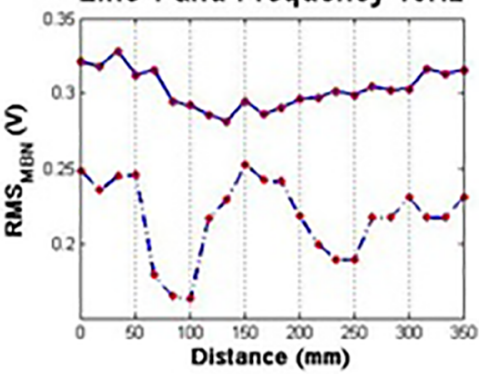

Graph sheet 1070 Line 1 and Frequency $10 \mathrm{~Hz}$

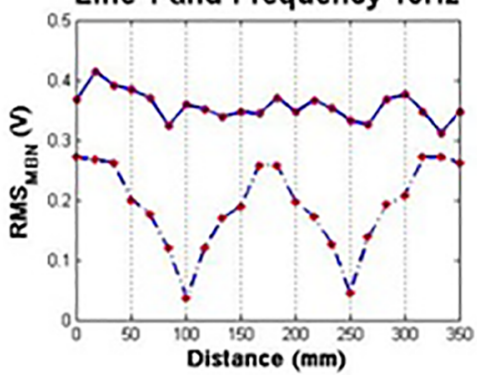

Graph sheet 1006 Line 2 and Frequency $10 \mathrm{~Hz}$

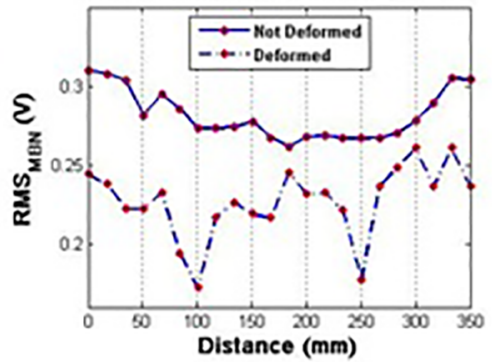

Graph sheet 1070 Line 2 and Frequency $10 \mathrm{~Hz}$

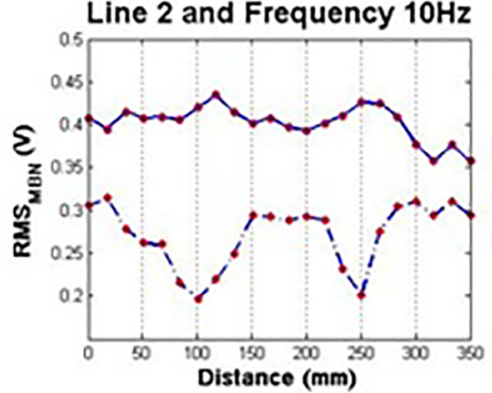

Graph sheet 1006 Line 3 and Frequency $10 \mathrm{~Hz}$

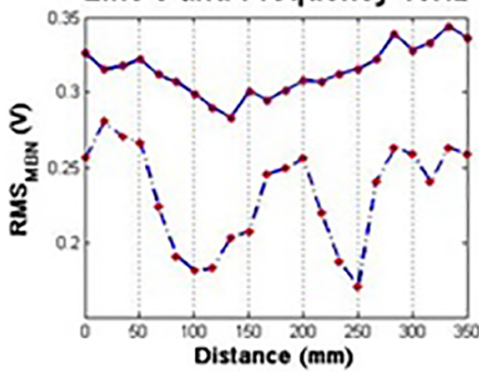

Graph sheet 1070

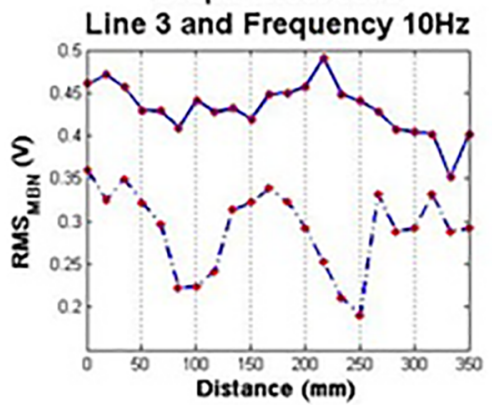

Figure 13. Graphs for SAE 1006 and 1070; Lines 1, 2 and 3; Frequency 10Hz; Speed 16 mm/s. 


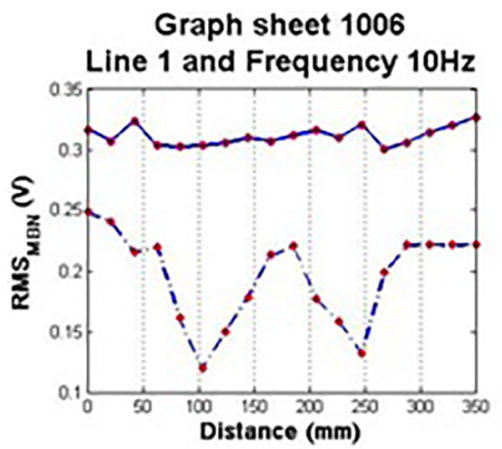

Graph sheet 1070 Line 1 and Frequency $10 \mathrm{~Hz}$

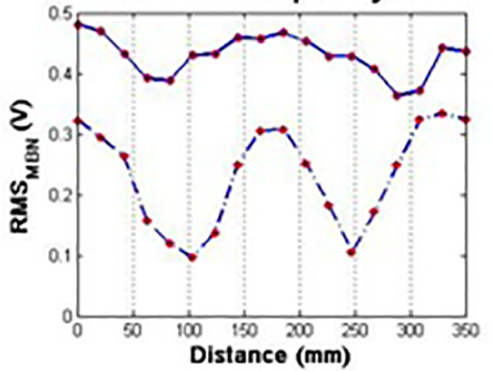

Graph sheet 1006 Line 2 and Frequency $10 \mathrm{~Hz}$

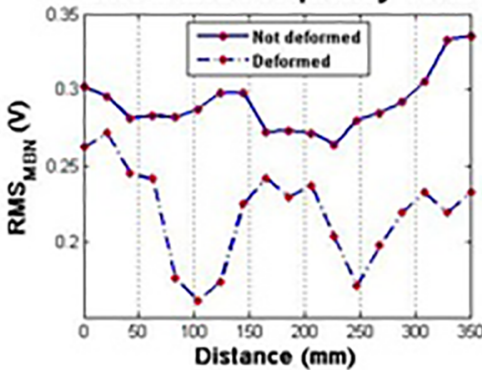

Graph sheet 1070 Line 2 and Frequency $10 \mathrm{~Hz}$

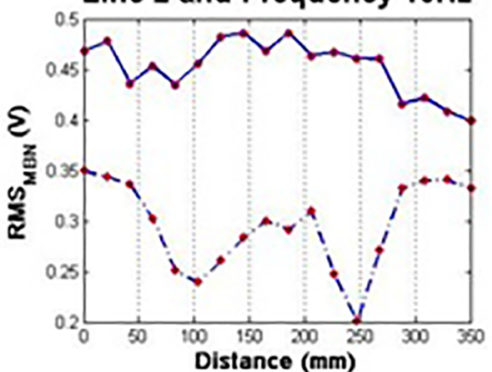

Graph sheet 1006 Line 3 and Frequency $10 \mathrm{~Hz}$

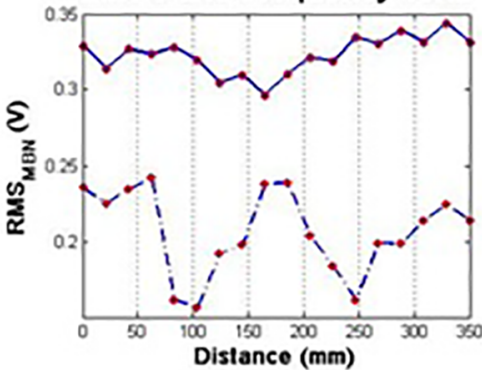

Graph sheet 1070 Line 3 and Frequency $10 \mathrm{~Hz}$

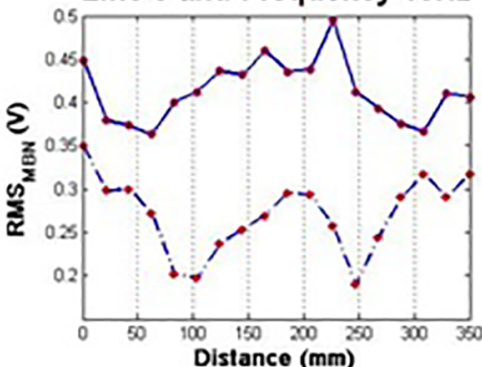

Figure 14. Graphs for SAE 1006 and 1070; Lines 1, 2 and 3; Frequency 10Hz; Speed 19 mm/s.

Graph sheet 1006 Line 1 and Frequency $10 \mathrm{~Hz}$

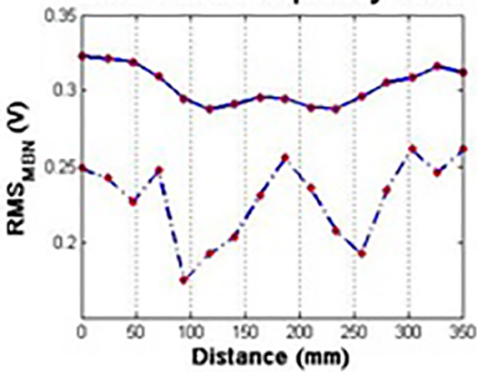

Graph sheet 1070 Line 1 and Frequency $10 \mathrm{~Hz}$

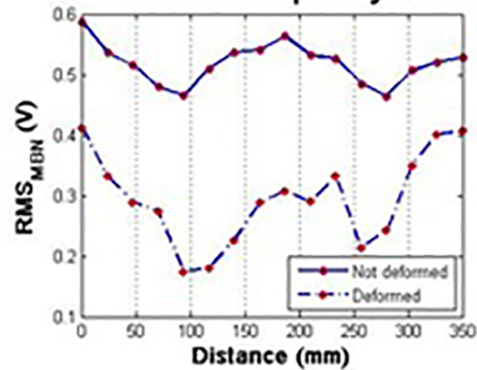

Graph sheet 1006 Line 2 and Frequency $10 \mathrm{~Hz}$

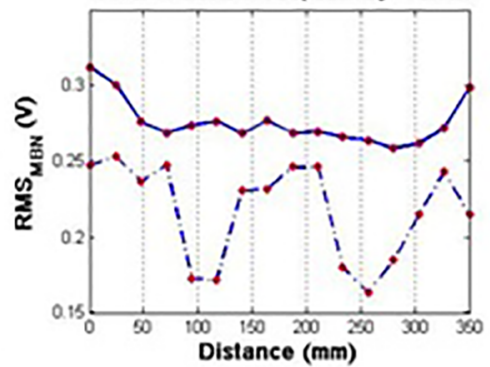

Graph sheet 1070 Line 2 and Frequency $10 \mathrm{~Hz}$

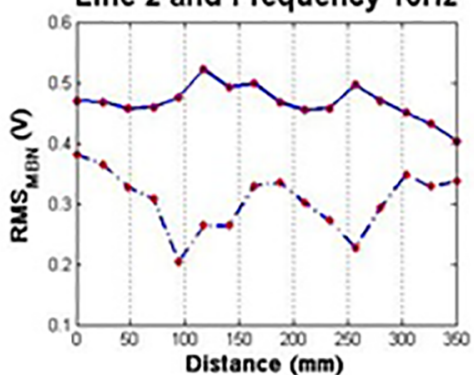

Graph sheet 1006 Line 3 and Frequency $10 \mathrm{~Hz}$

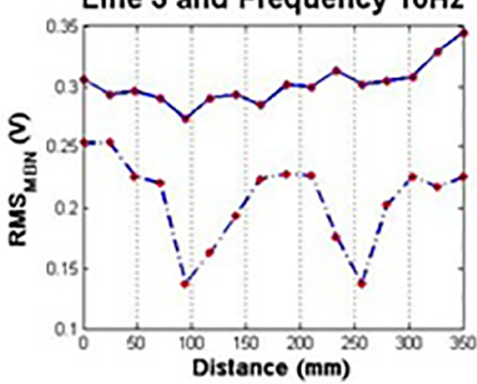

Graph sheet 1070 Line 3 and Frequency $10 \mathrm{~Hz}$

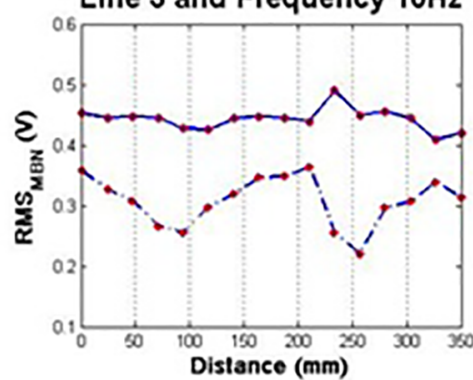

Figure 15. Graphs for SAE 1006 and 1070; Lines 1, 2 and 3; Frequency 10Hz; Speed 22 mm/s. 


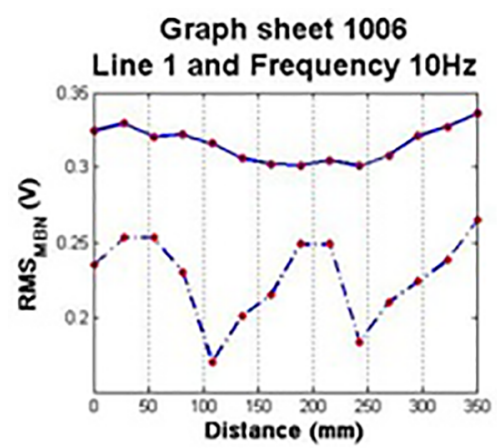

Graph sheet 1070

Line 1 and Frequency $10 \mathrm{~Hz}$

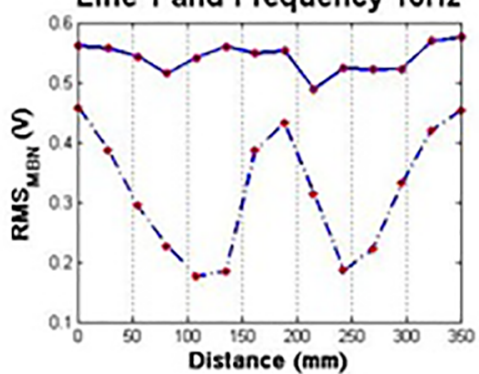

Graph sheet 1006

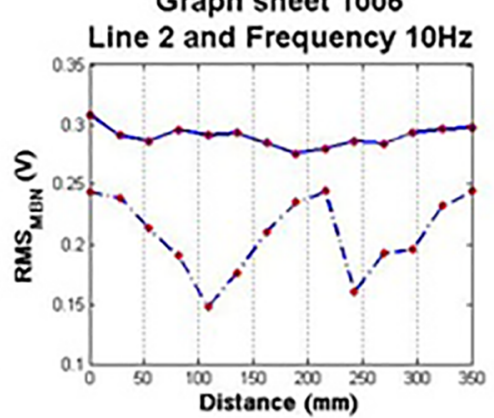

Graph sheet 1070 Line 2 and Frequency $10 \mathrm{~Hz}$

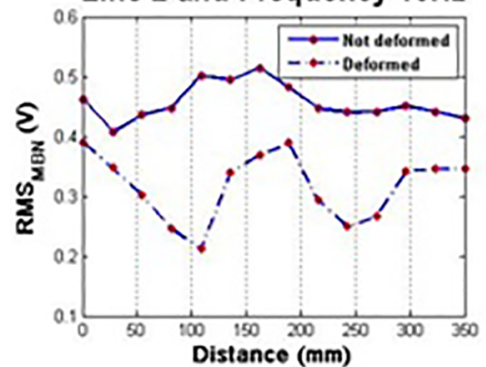

Graph sheet 1006 Line 3 and Frequency $10 \mathrm{~Hz}$

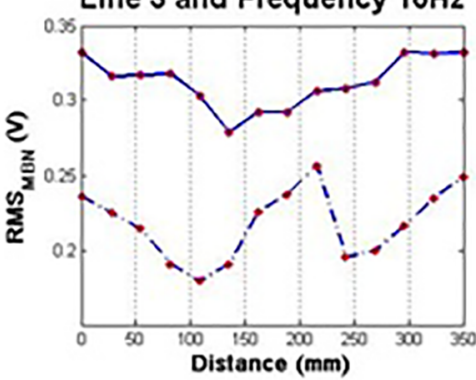

Graph sheet 1070 Line 3 and Frequency $10 \mathrm{~Hz}$

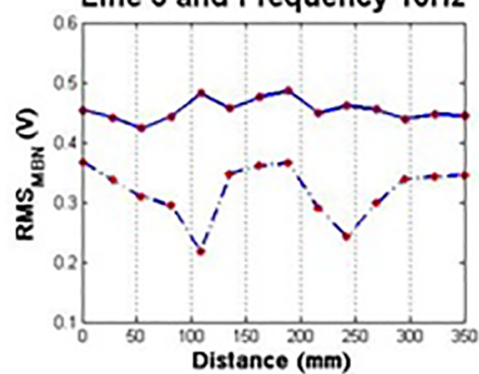

Figure 16. Graphs for SAE 1006 and 1070; Lines 1, 2 and 3; Frequency 10Hz; Speed 25 mm/s.

Graph sheet 1006

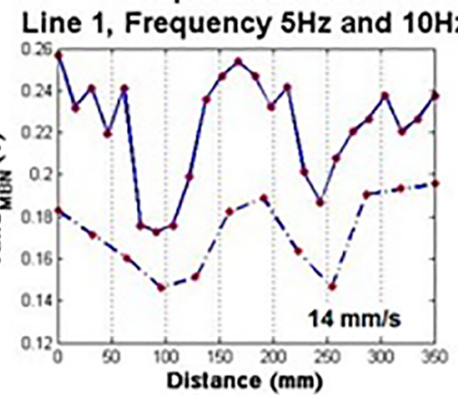

Graph sheet 1070

Line 1, Frequency $5 \mathrm{~Hz}$ and $10 \mathrm{~Hz}$

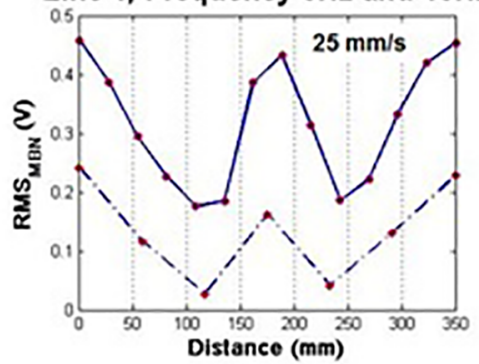

Graph sheet 1006

Line 2, Frequency $5 \mathrm{~Hz}$ and $10 \mathrm{~Hz}$

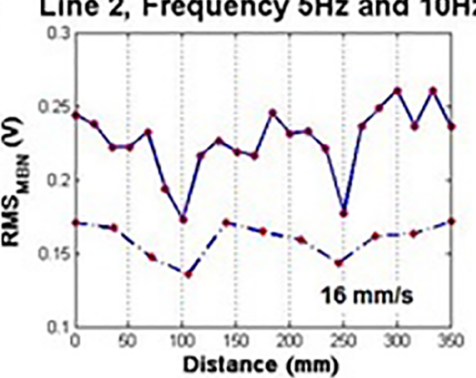

Graph sheet 1070

Line 2, Frequency $5 \mathrm{~Hz}$ and $10 \mathrm{~Hz}$

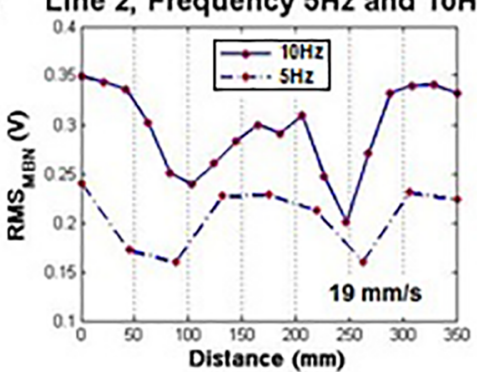

Graph sheet 1006
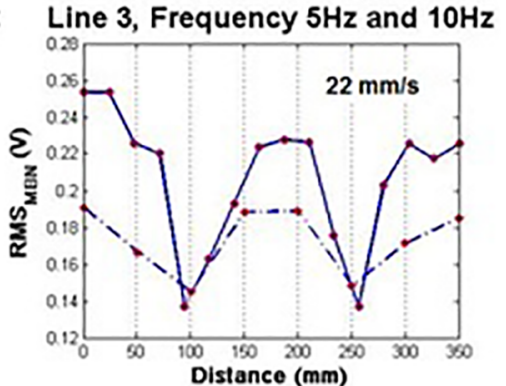

Graph sheet 1070

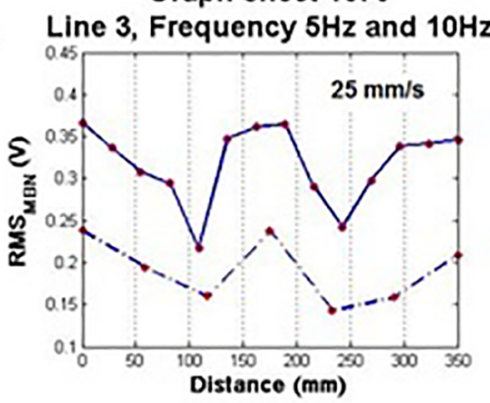

Figure 17. Comparison of $\mathrm{RMS}_{\mathrm{MBN}}$ curves for the two frequencies (5 and $10 \mathrm{~Hz}$ ), for SAE 1006 and 1070 steels. 
excitation frequency from 5 to $10 \mathrm{~Hz}$ causes the increase of $\mathrm{RMS}_{\mathrm{MBN}}$ values. The explanation is based on the fact that as the magnetization frequency increases, the number of jumps of the domain walls per unit of time also increases ${ }^{16,17}$. Therefore the amplitude of the signal and the $\mathrm{RMS}_{\mathrm{MBN}}$ parameter also increase.

With greater variations of magnetic flux in the material, wall motion avalanches are becoming more frequent, and the superposition of pulses in the measuring system is increased. Nevertheless, in all combination frequency-speed tested, the parameter $\mathrm{RMS}_{\mathrm{MNB}}$ followed in an acceptable way the location of the deformed zones in the samples.

\section{Conclusions}

A new approach to surface inspection NDT is described, based on Barkhausen Continuous Magnetic Noise Scan (CSMBN) technique.

The CSMBN technique was used on the evaluation for the detection of non-homogeneous zones of samples of low carbon SAE 1006 and high carbon SAE 1070 annealed steels. CSMBN was able to detect indentations with plastic deformation produced in both steels.

Five $(14,16,19,22$ and $25 \mathrm{~mm} / \mathrm{s})$ scan speeds and two excitation frequencies ( 5 and $10 \mathrm{~Hz}$ ) were tested. It was found that the quality of the diagnosis does not depend on the scan speed, within the range investigated. The increase of excitation frequency caused an increase of the $\mathrm{RMS}_{\mathrm{MBN}}$ parameter, but it did not affect the detection of plastic deformation spots.

Therefore, the CSMBN technique is a version of the traditional MBN technique, which retains all of its applicability as NDIT, adding speed and automation in the carbon steel sheet scanning process.

\section{Acknowledgements}

Authors are grateful to Brazilian Research agencies $\mathrm{CNPq}$ and CAPES for financial support.

\section{References}

1. Davut K, Gür CH. Monitoring the Microstructural Changes During Tempering of Quenched SAE 5140 steel by Magnetic Barkhausen Noise. Journal of Nondestructive Evaluation. 2007;26(2-4):107-113.

2. Park DG, Kishore MB, Lee DH, Kim JY, Jacobs LJ, Vertesy $\mathrm{G}$, et al. A study of microstructural analysis for nondestructive evaluation of thermal annealing using magnetic properties. NDT \& E International. 2017;89:14-18.
3. Kameda J. Characterization of tempered martensite microstructure and embrittlement by acoustic and magnetic Barkhausen signal measurement. Scripta Metallurgica. 1988;22(9):1487-1492.

4. Barkhausen H. Two with help of new repeating rediscovered appearances by $\mathrm{H}$ Barkhausen - The silence during unmagnetising of iron. Physikalische Zeitschrift. 1919;20:401-403.

5. Becker R, Döring W. Ferromagnetismus. Berlin Heidelberg: Springer-Verlag; 1939.

6. Chikazumi S. Physics of Ferromagnetism. $2^{\text {nd }}$ ed. New York: Oxford University Press; 1997. 668 p.

7. Jiles DC. Review of magnetic methods for nondestructive evaluation. NDT International. 1988;21(5):311-319.

8. Jiles DC. The effect of stress on magnetic Barkhausen activity in ferromagnetic steels. IEEE Transactions on Magnetics. 1989;25(5):3455-3457.

9. Crouch AE, Beuker T. In-Line Stress Measurement by the Continuous Barkhausen Method. In: Proceedings of 2004 International Pipeline Conference; 2004 Oct 4-8; Calgary, AB, Canada. p. 997-1003.

10. Desvaux S, Duquennoy M, Gualandri J, Ourak M. The evaluation of surface residual stress in aeronautic bearings using the Barkhausen noise effect. NDT \& E International. 2004;37(1):9-17.

11. Franco Grijalba FA. Desenvolvimento de Ensaio Não Destrutivo baseado no Ruído Magnético de Barkhausen para caracterização de tensões elásticas e deformações plásticas em aços. [Thesis]. São Paulo: University of São Paulo; 2010.

12. Franco FA, Padovese LR. NDT flaw mapping of steel surfaces by continuous magnetic Barkhausen noise: Volumetric flaw detection case. NDT \& E International. 2009;42(8):721-728.

13. Ilker Yelbay H, Cam I, Hakan Gür C. Non-destructive determination of residual stress state in steel weldments by Magnetic Barkhausen Noise technique. NDT \& E International. 2010;43(1):29-33.

14. Morgan MAC. Ruído magnético de Barkhausen contínuo rotacional. [Thesis]. São Paulo: University of São Paulo; 2013.

15. Padovese LR, Martin N, Millioz F. Time-frequency and Time-Scale analysis of Barkhausen. Proceedings of the Institution of Mechanical Engineers, Part G: Journal of Aerospace Engineering. 2009;223(5):577-588.

16. Haller TR, Kramer JJ. Observation of Dynamic Domain Size Variation in a Silicon-Iron Alloy. Journal of Applied Physics. 1970;41(3):1034.

17. Higuchi T. Magnetizing frequency dependence of magnetic domain size in $50 \%$ nickel-iron alloy deduced from a statistical analysis of core noise. Journal of Physics D: Applied Physics. 1974;7(17):2379-2385. 